Eleventh Floor, Menzies Building

Monash University, Wellington Road

CLAYTON Vic 3800 AUSTRALIA

Telephone:

(03) 9905 2398, (03) 99055112

Fax:

(03) 99052426

e-mail:

Internet home page: from overseas:

61399052398 or

61399055112

61399052426

impact@buseco.monash.edu.au http//www.monash.edu.au/policy/

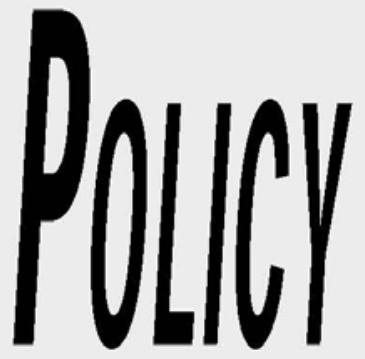

\title{
The Costs of Keeping Cool for Australians with Multiple Sclerosis
}

by

GEORGE VERIKIOS

Centre of Policy Studies

Monash University

MICHAEL SUMMERS

MS Australia

REX SIMMONS

Canberra Hospital

and

ZANFINA ADEMI

Department of Epidemiology and

Preventative Medicine

Monash University

General Paper No. G-190 August 2009

ISSN 10319034

ISBN 0732615976

The Centre of Policy Studies (COPS) is a research centre at Monash University devoted to economy-wide modelling of economic policy issues. 



\title{
THE COSTS OF KEEPING COOL FOR AUSTRALIANS WITH
}

\section{MULTIPLE SCLEROSIS}

\author{
George Verikios \\ Centre of Policy Studies, Monash University \\ Michael Summers \\ MS Australia \\ Rex Simmons \\ Canberra Hospital \\ Zanfina Ademi \\ Department of Epidemiology and Preventive Medicine, Monash University
}

\begin{abstract}
$\underline{\text { Abstract }}$
Heat intolerance is a significant medical problem affecting people with Multiple Sclerosis. For people with MS, the costs of running their air conditioners are an additional disease-related expense that must be met on top of other out-of-pocket disease-related expenses. Using the results of the 2008 Keeping Cool Survey, we estimate the relative economic disadvantage faced by MS households in trying to keeping cool. We find that MS households spend around ten times more on keeping cool than the average Australian household. Sensitivity analysis indicates that our results are robust with respect to all key parameters, across regions and nationally. Our results suggest that energy rebates for heat intolerant persons currently in place in Victoria and Western Australia should be implemented in other Australian states and territories.
\end{abstract}

JEL codes: $\quad$ I18

Keywords: cooling costs, economic disadvantage, energy rebates, heat intolerance, multiple sclerosis

\section{Acknowledgements}

Thanks are due to many people who made this research possible: members of the Australian Multiple Sclerosis Longitudinal Study (AMSLS) and their families; Gavin Dufty; Geoff Campbell; staff at the AMSLS, Canberra Hospital; volunteers at the ACT branch of MS Australia; Tribe Research; the Bureau of Meteorology. The project was funded by MS Research Australia, the Consumer Utilities Advocacy Centre (Victoria), the Public Interest Advocacy Centre (New South Wales), and the Consumer Advocacy Panel (www.advocacypanel.com.au). The views expressed here do not necessarily reflect the views of the sponsoring bodies, Monash University, Canberra Hospital, or MS Australia. 


\section{Table of contents}

1. Introduction 1

2. Aspects of multiple sclerosis 3

2.1 Multiple sclerosis and heat intolerance 3

2.2 The economic impact of MS 5

2.3 Climate 6

2.4 Air conditioner use in Australia 8

2.5 Policy context and the responses regarding the need for medical cooling 9

3. The Keeping Cool Survey 11

3.1 Method 11

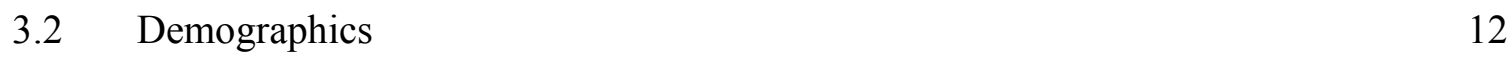

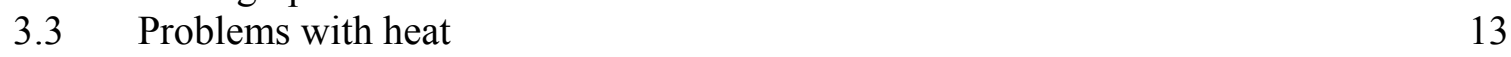

$\begin{array}{lll}3.4 & \text { Air conditioners and their use } & 14\end{array}$

$\begin{array}{lll}3.4 .1 & \text { Ownership } & 15\end{array}$

$\begin{array}{lll}3.4 .2 & \text { Types of air conditioning } & 15\end{array}$

$\begin{array}{lll}3.4 .3 & \text { Age of air conditioner } & 17\end{array}$

$\begin{array}{lll}3.4 .4 & \text { Size of space cooled } & 17\end{array}$

3.4.5 When is the air conditioner turned on? 18

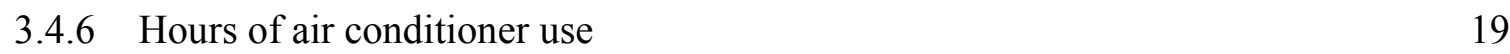

$\begin{array}{ll}3.5 & \text { Minor home modifications for thermal efficiency } 21\end{array}$

4. Estimated costs of air conditioning use by MS households 22

$4.1 \quad$ Base estimates 24

4.2 Sensitivity analysis 25

5. Conclusion 27

References 30

\section{Tables}

1 Average annual maximum apparent temperature for states/territories and $\begin{array}{lr}\text { capital cities } & 8\end{array}$

$2 \quad$ Number of survey participants by state and territory 13

$3 \quad$ Reasons given for not using an air conditioner 15

$4 \quad$ Percentage of people with minor home modifications 21

$5 \quad \begin{aligned} & \text { Estimated average cost of air conditioner use by MS households and all } \\ & \text { Australian households }\end{aligned}$

6 Sensitivity analysis of average cost of air conditioner use by MS households at $\$ 0.15 / \mathrm{kWh}$ to various parameters 26

\section{Figures}

1 Average number of hot days in Australia: 1957-2008 6

2 Average number of hot nights in Australia: 1957-2008 7

3 Proportion of people experiencing negative impacts from hot days and nights $\quad 14$

4 Type of air conditioner 16

$5 \quad$ Comparison of types of air conditioning between the KCS and ABS (2005) 17

6 Size of space cooled 18

$7 \quad$ Outside air temperature at which air conditioners are turned on 19

8 Imputed household average total hours of use for September to April 20 


\section{Introduction}

Multiple Sclerosis (MS) is a chronic, progressive and incurable disease that attacks the central nervous system, i.e., the brain and spinal cord. There are approximately 20,000 people with MS in Australia. ${ }^{1}$ Most people with MS are of working age and three-quarters are women (Access Economics 2005). Heat intolerance is a significant medical problem affecting people with MS; as little as $0.2^{\circ} \mathrm{C}-0.5^{\circ} \mathrm{C}$ increase in core body temperature creates an increase in MS symptoms for people with MS (Guthrie and Nelson 1995). Further, "Heat worsens and cooling improves negative symptoms of multiple sclerosis, sometimes dramatically so" (Baker 2002, p. 1779). As a consequence of their heat intolerance, people with MS in Australia use air conditioners extensively on hot days and nights out of medical need.

For people with MS, the costs of running their air conditioners are an additional diseaserelated expense that must be met on top of other out-of-pocket disease-related expenses. All of these expenses must be met from lower than average incomes that people with MS earn; in 2007, $52 \%$ of Australians with MS had annual incomes below $\$ 26,000$ (Australian Multiple Sclerosis Longitudinal Study (AMSLS), unpublished data). ${ }^{2}$ These out-of-pocket costs, combined with (a) relatively rapidly rising electricity costs, and (b) the increasing number of hot days and nights due to climate change, suggest that, over time, people with MS on low incomes are facing greater economic disadvantage in trying to keep cool on hot days and nights. But what is the current degree of economic disadvantage in trying to keep cool for people with MS? This work attempts to answer that question.

Notwithstanding the importance of keeping cool for people with MS, no previous research (that we are aware of) has explored and described the use of air conditioners by people with MS

\footnotetext{
1 This is an extrapolation for 2008 based on prevalence data in Access Economics (2005).

2 The AMSLS has been running since 2000, and has enrolled a large cohort of Australians with MS for interdisciplinary research relevant to improving their situation (see http://www.msaustralia.org.au/ $\mathrm{msra} /$ research/ms-life-study.php).
} 
across Australia, or in other countries. To address this absence, the Keeping Cool Survey (KCS) was conducted. ${ }^{3}$ The KCS was sent to 3,150 people with MS in September 2008; it had an impressively high response rate of $76 \%$. Key issues covered by the survey included: what happens when a person with MS gets too hot; the use of air conditioning to keep cool; outside air temperature when air conditioners are turned on; the type, age and hours of use of air conditioners; and minor home modifications related to keeping cool. There was an overlap of 1,578 respondents $(66 \%)$ to both the KCS and two previous Economic Surveys conducted as part of the AMSLS. This enabled analysis regarding air conditioning use by people with MS who are likely to be eligible for a concession or rebate for their electricity bills.

Using the results of the $\mathrm{KCS}$, we estimate the average hours of air conditioner use by people with MS in seven of the eight Australian states and territories, and nationally. Applying a range of electricity prices to these use estimates, and adjusting for the efficiency of air conditioners and cooling loads across regions, we estimate the average cost of running air conditioners by people with MS over the warmer months of the year. These results are then compared to similar averages for the average consumer. The results give an indication of the degree of economic disadvantage suffered by people with MS in their attempt to minimise the negative medical effects of heat intolerance; such estimates are also unprecedented.

Given that more than half of Australians with MS have annual incomes below $\$ 26,000$, the economic disadvantage suffered by people with MS raises a number of public policy issues and challenges:

- ensuring that community service obligations to people who are heat intolerant are met in a way that is effective and equitable;

- maximising the efficiency of cooling for these households to minimise both the economic and environmental costs; and

\footnotetext{
3 The survey was conducted within the framework of the AMSLS; see footnote 2.
} 
- minimising the impact of catastrophic events such as power-blackouts on this group.

These public policy issues and challenges must be resolved in ways that will continue to be effective and equitable in a rapidly changing policy environment that includes:

- the development of national electricity markets;

- the implementation of smart meters, and time-of-use peak pricing tariff structures;

- rapidly increasing electricity costs now and into the foreseeable future; and

- more hot days and nights nationally, increasing the need for medical cooling and the associated increasing costs for households.

The estimates presented here are an important input into any policy responses that aim to reduce the economic burden of heat intolerance in an effective and equitable manner.

\section{Aspects of multiple sclerosis}

\subsection{Multiple sclerosis and heat intolerance}

Heat intolerance has been known to be a significant issue for people with MS since the late $19^{\text {th }}$ century. Guthrie and Nelson's (1995) critical review of the influence of temperature changes on MS traces the scientific and medical understanding of the issue from Uhthoff's work in 1890 to more recent work. Two key points emerge from their review: (a) internationally, MS symptoms increase in about $80 \%$ of people with MS when they get too warm, and (b) the exact physiological cause cannot be fully explained through the usual hypothesis that heat blocks the nerve conduction of already damaged (demyelinated) axons of nerve cells.

Heat is generally associated with an increase in MS symptoms such as blurred vision, extreme fatigue, muscle weakness, pain, tremors, memory problems, loss of balance, bladder and bowel problems, numbness and tingling, decreases in cognitive function, and in severe instances partial or complete paralysis (Guthrie and Nelson 1995; Simmons et al. 2001; Lerdal et al. 
2007). ${ }^{4}$ Paradoxically, while exposure to the cold is generally helpful and reduces MS symptoms (NASA/MS Cooling Study Group 2003; Petrilli et al. 2004; Meyer-Heim et al. 2007), some people with MS (5-30\%) have a worsening of symptoms in the cold (Simmons et al. 2001; Visscher et al. 1983).

Heat intolerance has significant economic and quality of life impacts in the day-to-day lives of people with MS and their families (De Judicibus and McCabe 2007). Also, managing heatrelated problems is a key component in ensuring that people with MS are able to retain employment (Johnson and Fraser 2005). These findings are reinforced by a survey of 2,500 people with MS that found that exposure to high temperatures was one of the three most commonly cited adverse factors in relation to their MS symptoms (Simmons et al. 2001). It is generally believed that symptoms usually return to their baseline status when the body temperature returns to normal. But Guthrie and Nelson (1995) and others (see, for example, Edlich 2004) note that on rare occasions the increase in symptoms is not reversible.

In a meta-analysis of six reports on seasonal variations in MS onsets and exacerbations, a statistically significant difference was found with the highest frequencies in spring and the lowest in winter (Ya-Ping et al. 2000). In their study of seasonal variations in Japan, Ogawa et al. (2003) found that there were more frequent exacerbations in the warmest months, and the coldest. This was attributed to the probable impact of increased viral infections in cold months and warmer weather in spring and summer. In contrast, Tataru et al. (2006) unexpectedly found no increase in MS relapses during the 2003 heat wave in France. Nevertheless, they did note that one of several possible explanations for this was that people with MS are well aware of the problems heat causes them, and that they take appropriate precautions during hot weather.

\footnotetext{
4 Also, while it is rare, there are reports of deaths from heat in people with MS. See, for example, Guthrie (1951) (cited in Guthrie and Nelson (1995)), Kohlmeier et al. (2000), and Henke et al. (2000).
} 
While it is clear that heat exacerbates MS symptoms, results from epidemiological studies of patterns in exacerbations in relation to seasonal climate variations are confounded by other sources of exacerbations (such as viral infections), and the modifying behaviours of people with MS who routinely take precautions to minimise their exposure to heat on hot days and nights whenever possible.

\subsection{The economic impact of MS}

There are significant economic costs associated with having MS. Access Economics (2005) found that the average annual costs in 2005 to people with MS and their families in Australia was $\$ 10,500$ (\$3,893 out-of-pocket and $\$ 6,593$ for informal care). These costs are likely to have increased in the last four years, making the additional cost of running an air conditioner particularly burdensome for most people with MS. These very significant economic costs are borne by people with MS and their families across the financial spectrum. But like other people in the community with chronic illnesses, overall, people with MS have lower income levels than the general community. Although $87 \%$ of people with MS are of working age, and most people with MS are employed when first diagnosed, $80 \%$ are not employed 10 years after diagnosis (Access Economics 2005). One result of this is that 52\% of Australians with MS have annual incomes below $\$ 26,000$ (AMSLS, unpublished data); ${ }^{5}$ this compares to an Australian average of $\$ 43,966$ for total earnings for all employees. ${ }^{6}$ So although many people with MS are initially employed, ultimately most end up on fixed incomes provided through part and full pensions. This combination of low incomes and the high economic costs of MS means that concessions such as energy rebates are often a critical financial factor in their daily lives.

\footnotetext{
5 This is for 2007.

6 This is an annualised figure for 2006-07 based on data in ABS (2009).
} 


\subsection{Climate}

Air conditioner use by people with MS in Australia is a direct response to day-to-day weather; an increase in the number of hot days and nights will increase the use of electricity by people with MS in their efforts to keep cool. One of the difficulties of examining climatic impacts on the use of air conditioners by people with MS is the wide variability of the weather across Australia. Additionally, air temperature data has significant limitations because moderate to high levels of humidity, coupled with hot days and nights, make it more difficult for people to keep cool.

Summary climate data is presented below to give an overview of some of the key issues. Figures 1 and 2 present national averages for the annual number of hot days $\left(35^{\circ} \mathrm{C}\right.$ and over) and hot nights $\left(20^{\circ} \mathrm{C}\right.$ and over) for the last 50 years. On average, these demonstrate a clear trend towards more hot days and nights. Significantly, $35^{\circ} \mathrm{C}$ is a very high temperature for most people with MS; the KCS results found that, on average, people with MS turn on their air conditioner when the outside temperature reaches $29^{\circ} \mathrm{C}$, with many turning it on well before then (see Section 3.4.5).

Figure 1 Average number of hot days in Australia: 1957-2008

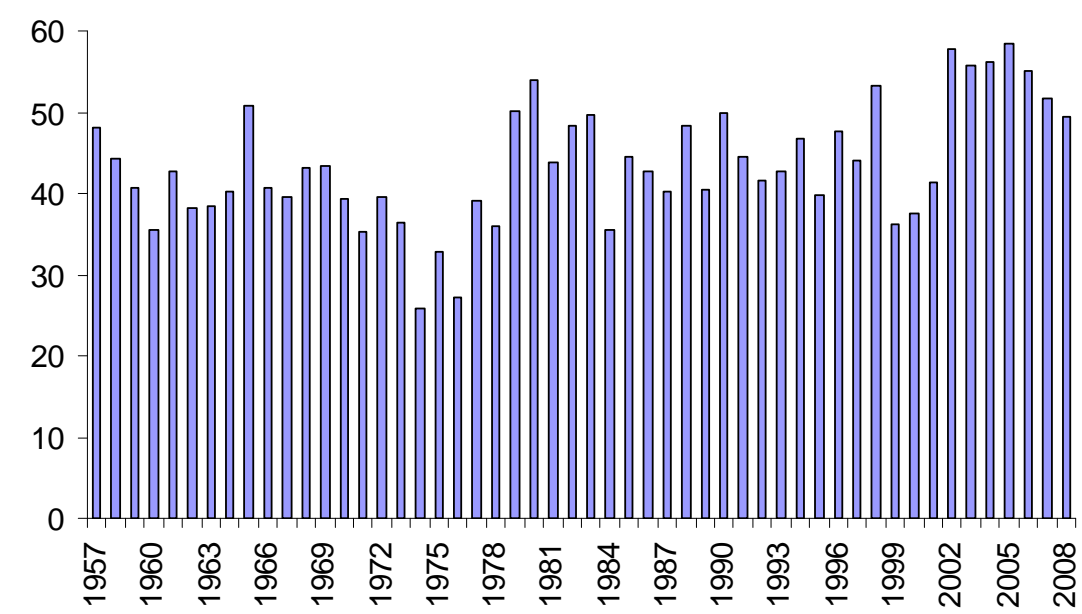

Source: Bureau of Meteorology (http://www.bom.gov.au/cgi-bin/silo/reg/cli_chg/extreme_timeseries.cgi). 
Figure 2 Average number of hot nights in Australia: 1957-2008

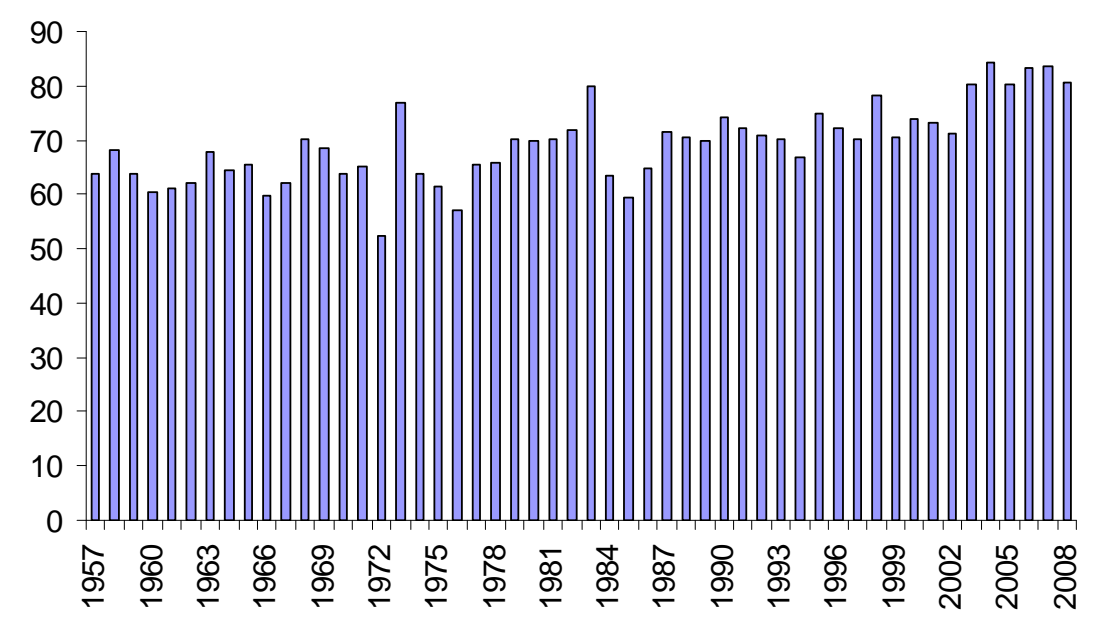

Source: Bureau of Meteorology (http://www.bom.gov.au/cgi-bin/silo/reg/cli_chg/extreme_timeseries.cgi).

Table 1 presents the apparent temperature (AT) data averaged over 30 years (from 19762005) for states/territories and capital cities. AT is an adjustment to the ambient air temperature based on the level of humidity: the adjustments use absolute humidity with a dew point of $14^{\circ} \mathrm{C}$ as the reference point (with slight adjustments depending on the temperature). If the humidity is higher than the reference point then the AT is higher than the air temperature, and if the humidity is lower than the reference point, then the AT is lower than the air temperature.

Table 1 is ordered from highest to lowest AT, and capital cities are included as state/territory averages may misrepresent impacts on populations given their uneven distribution throughout each region. Thus, data for capital cities may be a better representation of actual impacts on the population given that this is where populations tend to be concentrated in Australia.

Although the above figures and table give a useful overview of climate data, it should be noted that such broad-brush figures obscure the wide variations across seasons and across locations. Further, it is also difficult to translate these broader figures into what this means in relation to hot days and hot nights that would adversely affect someone with MS. 
Table 1 Average annual maximum apparent temperature for states/territories and capital cities

\begin{tabular}{lcc}
\hline & \multicolumn{2}{c}{ Apparent temperature (Celsius) } \\
State/territory & Capital city \\
\cline { 2 - 3 } Northern Territory & 31.2 & 35.0 \\
Queensland & 30.2 & 27.0 \\
Western Australia & 28.0 & 24.1 \\
South Australia & 25.0 & 21.4 \\
New South Wales & 23.1 & 22.9 \\
Victoria & 19.5 & 19.7 \\
Australian Capital Territory & 16.4 & 18.9 \\
Tasmania & 15.8 & 16.5 \\
\hline
\end{tabular}

Source: Data was compiled for MS Australia by the Bureau of Meteorology in 2008, and represent 30 year averages from 19762005.

\subsection{Air conditioner use in Australia}

There have been several Australian reports in recent years regarding air conditioners, climate and/or energy use, such as de Dear and Hart (2002) for New South Wales (NSW) and RMR (2008) for Victoria. One of the most important works is ABS (2005), which is a national survey; it includes a significant section on Australian air conditioner ownership and use patterns, as well as other relevant material on household construction as it relates to thermal efficiency and energy use generally. The results from ABS (2005) are reported here as a benchmark for Australian households.

The most comprehensive national estimates and projections for energy use in relation to household cooling and air conditioner use are in DEWHA (2008), which estimates that electricity for space cooling nationally is at $4 \%$ of average household energy use (p. 25). In 2007, the Victorian Utility Consumption Household Survey was conducted (RMR 2008) involving a stratified random sample of 2,061 households. The results for air conditioner ownership and use are reported here as a benchmark for Victorian households. 


\subsection{Policy context and responses regarding the need for medical cooling}

The major issues shaping public policy developments in relation to residential electricity include the development of national electricity markets, the implementation of smart meters, rapidly increasing electricity costs and related environmental measures to reduce demand and carbon emissions.

Nationally, electricity prices have risen 31\% above the consumer price index since 1990 (and over $80 \%$ for Melbourne over the same period, Dufty 2009), and this trend is likely to accelerate. For example, the Independent Pricing and Regulatory Tribunal in NSW has proposed price increases for the next year (i.e., 2010) of between $18.5 \%$ and $21.5 \%$ (IPART 2009). Major drivers of these increasing costs are: rising fuel costs; increasing infrastructure and maintenance costs; increased demand; new construction costs; and implicit carbon taxes. ${ }^{7}$

Smart meters are gradually being introduced in many parts of Australia. Smart meters are being strongly promoted as means of increasing efficiency, reducing energy use and greenhouse gas emissions, and improving the capacity of consumers to self-manage their electricity use through better information. Costs of installing smart meters will be passed on to consumers. Smart meters enable: consumption to be measured and charged in small time increments such as half-hours; differential pricing during peak (and low) consumption times (time-of-use pricing); back-to-base remote monitoring and control; and the possibility of add-ons such as in-home monitoring of electricity consumption.

Differential pricing (time-of-use pricing) is likely to particularly disadvantage people with a medical need to keep cool who are not at work, as peak-pricing hours are often during working hours; thus, they will have to pay maximum prices out of relatively low and fixed incomes. The use of smart meters to implement time-of-use tariff structures is likely to create a serious 
financial burden on people with MS (and other heat intolerant conditions) given their air conditioner use and cost is approximately ten times higher than that of average Australian households (see Sections 3.4 and 4.1).

The Ministerial Council on Energy (2008: p. 3), in its response to the Council of Australian Governments' request for a national review of community service obligations and advice on best practice, observed that:

“Energy...plays an important role in maintaining Australians' living standards...In order to facilitate the provision of energy to vulnerable customers, Governments can create a range of CSOs [community service obligations] to assist those in need...Governments can ensure the delivery of energy CSOs by...subsidies to retailers for providing non-commercial services and concessions on bills for classes of consumers to assist them to pay energy bills...State and Territory governments are responsible for delivering energy CSOs."

To date, two governments have responded to the need to provide assistance to people with MS (and other heat intolerant conditions): Western Australia (WA) and Victoria. The WA government implemented a Thermoregulatory Dysfunction Subsidy Scheme in January 2007. The projected annual budget is $\$ 500,000$ to provide 1,500 people with $\$ 335$ annually for assistance with heating and cooling costs as a result of a medical condition.

In Victoria, the Medical Cooling Concession (previously known as the MS Summer Concession) was implemented approximately 10 years ago, and has provided a discount of $17.5 \%$ on summer (December-February) electricity bills for those eligible. In July 2008, the concession was expanded to 6 months of coverage (November-April), and the annual budget commitment was increased from $\$ 102,500$ in $2007-08$ to $\$ 2.4$ million over 5 years ( $\$ 625,000$ annual average). In 2007-08 the Victorian concession assisted 4,313 households. It is estimated that approximately $1,500-1,800$ of these were people with MS.

\footnotetext{
${ }^{7}$ Implicit carbon taxes are already in place across Australia via the Australian Government's Mandatory Renewable Energy Target scheme (see http://www.orer.gov.au/publications/mret-overview.html), and similar state and territory schemes, that are imposed on electricity wholesalers.
} 


\section{The Keeping Cool Survey}

In this section we report on the most important results from the KCS, including the sociodemographic profile of people with MS and other results that are used as inputs to estimate the costs of keeping cool of people with MS. In general, national results are reported, although for some key issues, state and territory level results are presented. ${ }^{8}$

\subsection{Method}

The KCS was sent to 3,150 people with MS in September 2008; there were 2,385 responses (76\%). ${ }^{9}$ Of these respondents, there was an overlap of 1,578 respondents $(66 \%)$ across the KCS and two Economic Surveys conducted in 2003 and 2007 as part of the AMSLS. For the 1,578 participants for whom economic data was available, we compared responses with the KCS to determine those who would probably be 'concession eligible' (those on Aged Pensions, Disability Support Pensions, Department of Veterans Affairs benefits and/or Healthcare Card Holders) and those who were not. We found no systematic differences in responses to the KCS between the two groups. As such, results for the whole sample are presented below.

This lack of difference is itself a major research finding. It was expected that those who are concession eligible would be less able to afford the ownership and operation of air conditioners and have lower rates of air conditioner ownership and use. But this is not the case. Likely explanations would appear to reside in three interrelated possibilities:

(a) the medical need to keep cool is a very high priority for people with MS, so the impact of different income levels on ownership and use of air conditioners is minimal;

\footnotetext{
${ }^{8}$ Appendix C of Summers and Simmons (2009) contains more detailed results for some survey questions. Results from the Northern Territory are not reported as the number of participants was too small to be meaningful or valid.

${ }^{9}$ See Appendix A of Summers and Simmons (2009) for a copy of the survey.
} 
(b) even for those people with MS who are relatively better off financially, the overall economic impact of MS may operate to encourage them to use their air conditioners only when absolutely necessary; and

(c) price signals combined with increasing awareness and concern about environmental costs moderate usage patterns equally across both groups.

Following a brief overview of the survey participants' demographics, results are reported in summary form.

\subsection{Demographics}

Over three-quarters (79\%) of respondents to the KCS are female. Overall, the mean age of the participants was 52 years, with a range of $25-83$ years. This gender and age distribution approximates that of the Australian MS population: $74 \%$ female, and prevalence rates peak between the ages of 40 and 59 (Access Economics 2005). Approximately $36 \%$ of those surveyed are likely to be eligible for a concession or rebate on their electricity bills. This estimate assumes that eligibility for any concession will include people with MS who are heat intolerant, and who have Disability Pension, Aged Pension, are receiving benefits from Department of Veterans' Affairs, and/or have a Healthcare Card. Of the remainder, approximately 54\% would not be in receipt of one of these benefits and $10 \%$ do not have a problem with heat. As a consequence of the lack of differences in KCS responses between those that are and those that are not likely to be eligible for a medical cooling concession or rebate, the results presented below can be interpreted as being equally applicable to both groups, and to people with MS generally.

The proportion of survey participants in each state and territory (Table 2) broadly corresponds to the number of people with MS in each region, as judged from the membership numbers of MS societies across Australia. There are very few people with MS in the NT, 
probably because of the heat, but also because the disease has a known 'latitudinal gradient' of occurrence, with a greater incidence and prevalence away from the equator.

Table 2 Number of survey participants by state and territory

\begin{tabular}{lcc}
\hline State/territory & Number of Participants & Percentage \\
\hline Northern Territory & 4 & 0 \\
Queensland & 317 & 13 \\
Western Australia & 234 & 10 \\
South Australia & 200 & 8 \\
New South Wales & 755 & 32 \\
Victoria & 682 & 29 \\
Australian Capital Territory & 70 & 3 \\
Tasmania & 123 & 5 \\
\hline Australia & 2,385 & 100 \\
\hline
\end{tabular}

\subsection{Problems with heat}

Only $10 \%$ of the survey participants stated that they did not have a problem with heat. Figure 3 sets out the proportion of survey participants who experience a wide range of different health and lifestyle impacts as a consequence of hot days and hot nights. The frequency with which people reported these problems did vary across states and territories: see Appendix C of Summers and Simmons (2009) for further details.

Figure 3 emphasises that the most common problem people with MS experience when they get too hot is an extreme form of fatigue, with most experiencing a general increase in their other MS symptoms as well. Additionally, approximately half find the heat renders them unable to participate in social activities, normal household duties and in the workforce. While almost $10 \%$ require more medication, or a visit to a doctor or other health professional, $3 \%$ report having been hospitalised as a consequence of the impact of heat on their MS symptoms. 
Figure 3 Proportion of people experiencing negative impacts from hot days and nights

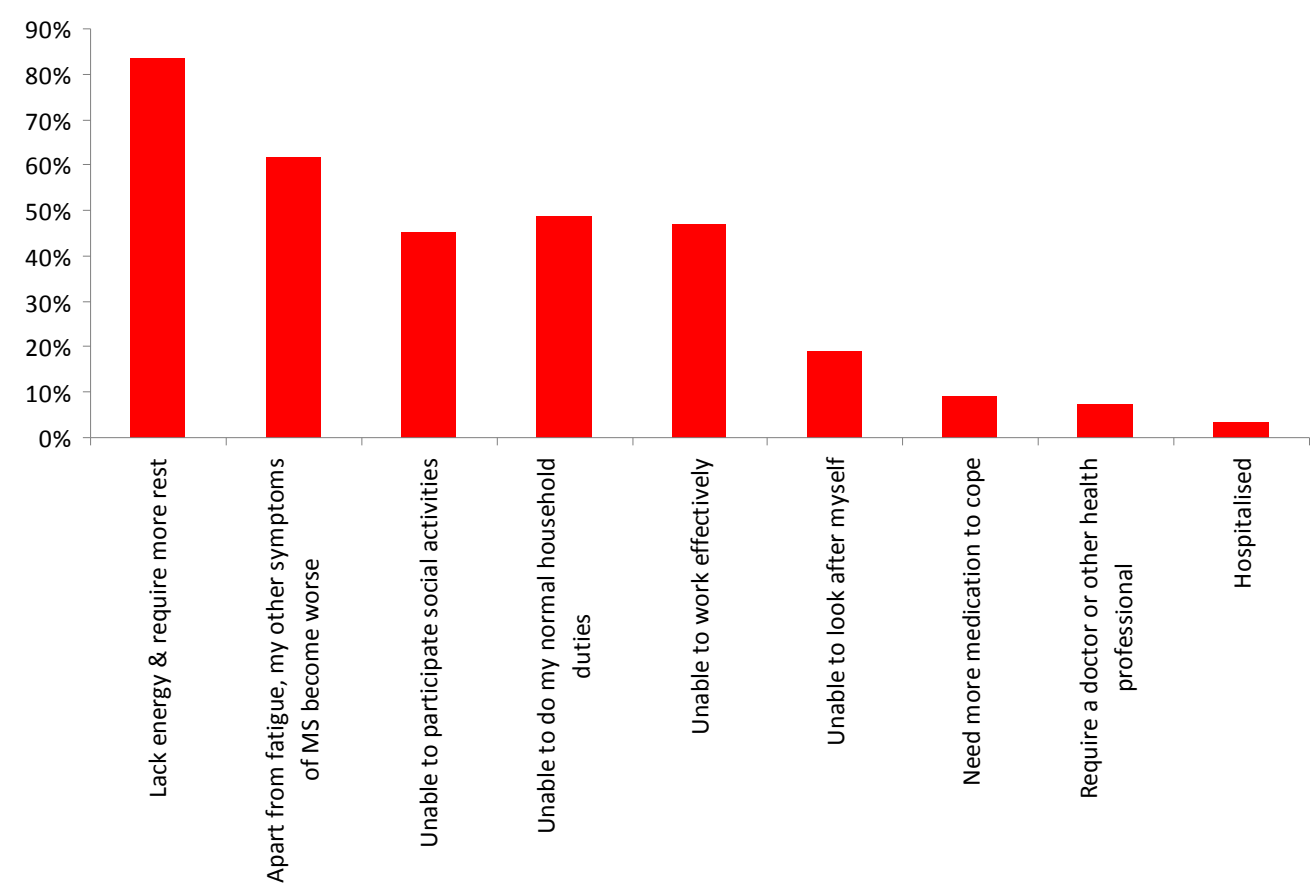

While these are relatively small proportions overall in relation to needing some form of medical care, it does serve to highlight the seriousness of this issue for people with MS. The small proportions here are also probably a sign of how well and how much effort and attention people with MS put into managing their exposure to heat, and is an indication of what can happen if they cannot keep cool enough.

\subsection{Air conditioners and their use}

Here we report a number of issues to do with air conditioners: the types of air conditioners used; their age; the size of the space cooled; and the hours of operation across the year. This information is key to modelling the costs incurred in order to keep cool as it forms the basis for such modelling. 


\subsubsection{Ownership}

Of the survey participants, $82 \%$ were using air conditioners to keep cool, with a range of $80-90 \%$ (except Tasmania where 53\% were using air conditioners). This is a high level of air conditioner use relative to the national population; in $2005,60 \%$ of all households nationally had an air conditioner (ABS 2005: p. 50). Of the 431 (18\%) participants who were not using an air conditioner, 391 indicated a reason for this as outlined in Table 3.

Table 3 Reasons given for not using an air conditioner

\begin{tabular}{lccc}
\hline Reason & Number & $\begin{array}{c}\text { Percentage of those not } \\
\text { using an air conditioner } \\
(\mathrm{n}=431)\end{array}$ & $\begin{array}{c}\text { Percentage of Total } \\
\text { Sample Response } \\
(\mathrm{n}=2,370)\end{array}$ \\
\hline $\begin{array}{l}\text { No problem with hot weather } \\
\text { Cannot afford an air }\end{array}$ & 127 & $32 \%$ & $5 \%$ \\
conditioner & 228 & $58 \%$ & $10 \%$ \\
Cannot afford the electricity & 25 & $6 \%$ & $1 \%$ \\
Broken air conditioner & 11 & $3 \%$ & $0 \%$ \\
\hline
\end{tabular}

\subsubsection{Types of air conditioning}

Figure 3 describes the different types of air conditioners used. Nationally, approximately $56 \%$ were split systems, $21 \%$ were ducted, $19 \%$ were evaporative, and $14 \%$ had window units. It should be noted that this question is partly ambiguous, as 'ducted' can be either evaporative or refrigerated/reverse-cycle. Across the general population in Victoria, evaporative air conditioners account for five times as many ducted systems as refrigerated/reverse-cycle air conditioners (RMR 2008: p. 117). Although evaporative air conditioners are much less expensive to operate (approximately one-eighth the cost of reverse-cycle air conditioners for ducted systems), in humid climates they are ineffective.

Comparative data are available on types of air conditioners used by households across regions (ABS 2005). Figure 4 compares air conditioner types (evaporative and 
refrigerated/reverse cycle) between the KCS and ABS (2005). Proportions in the two surveys are remarkably similar across regions, with the exception of the Australian Capital Territory. To create comparable data, the KCS categories of split system and window units were combined to create 'refrigerated/reverse cycle', and ducted systems are not incorporated (as noted above they could be either evaporative or refrigerated). So although ownership of air conditioners is higher for people with MS, the type of air conditioners used is similar to national trends for different locations.

\section{Figure 4 Type of air conditioner}

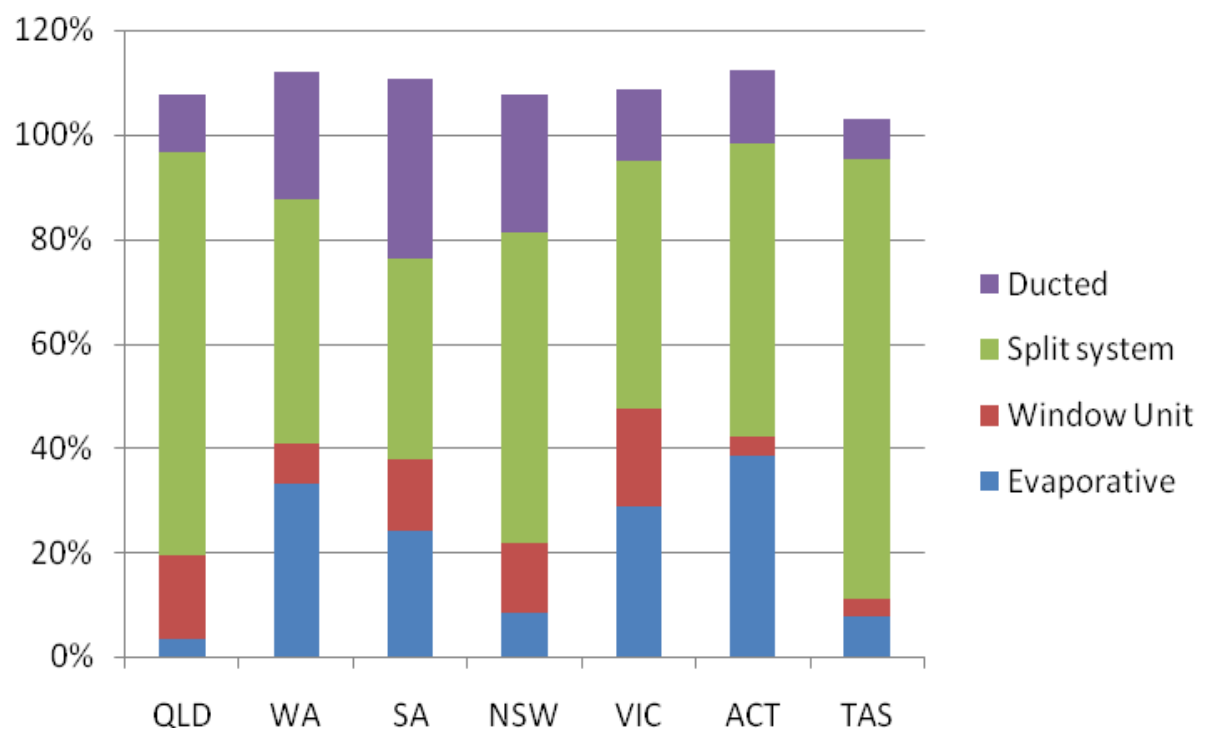

Note: Percentages exceed $100 \%$ because a small number of people had more than one type of air conditioner. 
Figure 5 Comparison of types of air conditioning between the KCS and ABS (2005)

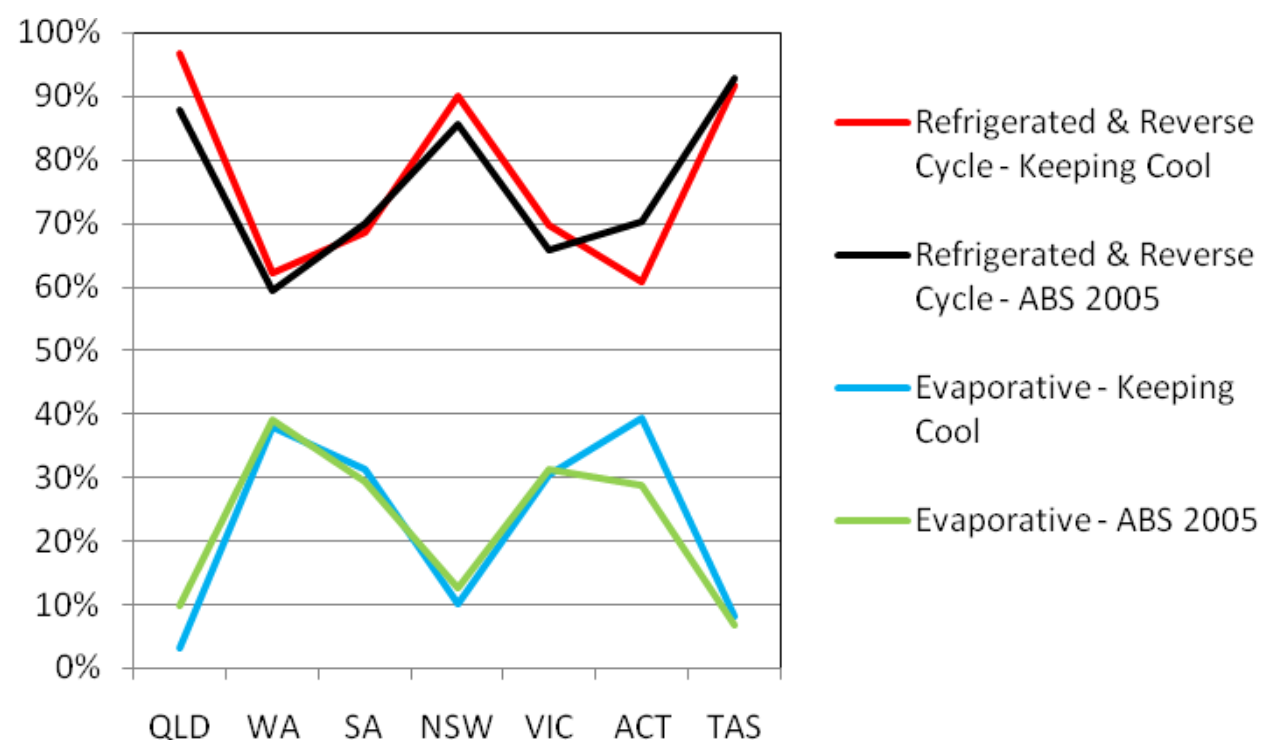

\subsubsection{Age of air conditioner}

The age of a refrigerated/reverse-cycle air conditioner is an indicator of its efficiency. If it is more than 3 years old, it is very unlikely to have inverter technology, which increases cooling efficiency by $20-25 \%$. Similarly, air conditioners that are 10 or more years old are likely to be even less efficient as a consequence of less efficient designs and the increased likelihood of requiring maintenance and/or repairs to optimise efficiency. The national distribution of the age of refrigerated/reverse-cycle air conditioners from the survey is as follows: $36 \%$ are in the range $0-3$ years; $43 \%$ are in the range $4-9$ years; and $21 \%$ are $10+$ years old.

\subsubsection{Size of space cooled}

Another critical element in relation to air conditioner use (and energy consumption and cost) is the size of the space being cooled. Figure 5 summarises the data across regions. 
Figure 6 Size of space cooled

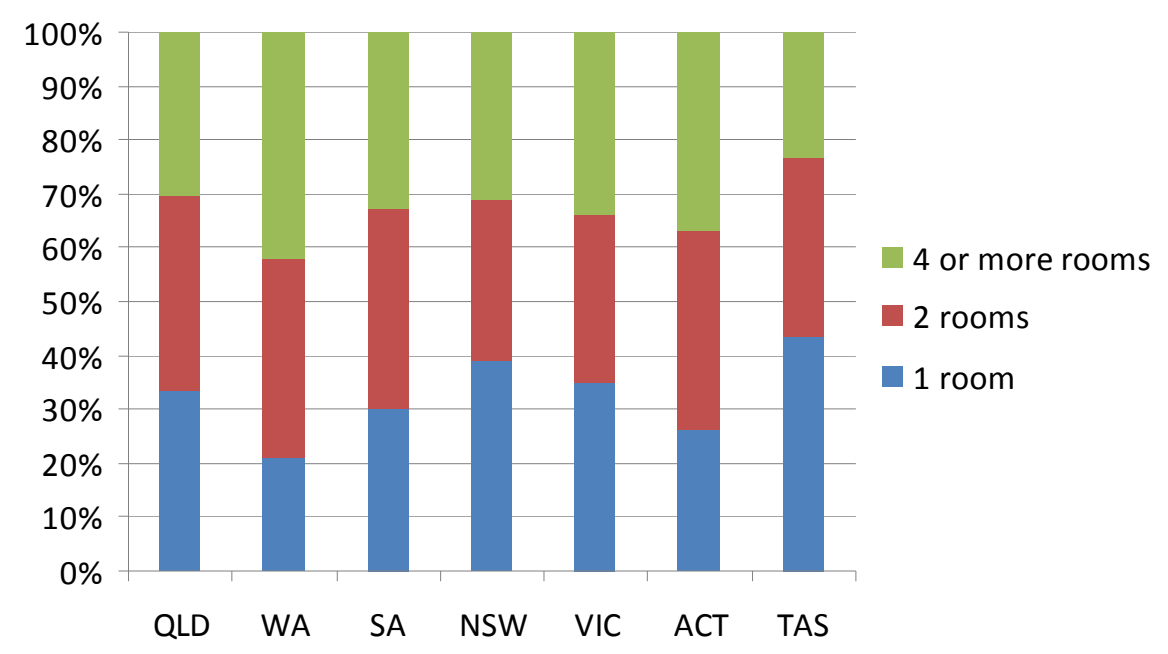

When these figures are averaged nationally there is an almost perfectly even distribution across the three categories: $34 \%$ ( 1 room); $33 \%$ ( 2 rooms); and 33\% (4 or more rooms). This also reflects the regional distribution with two exceptions: WA had more ' 4 or more rooms' responses (42\%) and fewer ' 1 room' responses (21\%); Tasmania had fewer ' 4 or more rooms' responses $(23 \%)$ and more ' 1 room' responses (44\%). No survey participants stated that they cooled 3 rooms.

\subsubsection{When is the air conditioner turned on?}

Figure 6 summarises the results regarding the external air temperature at which people with MS turn on their air conditioners. One of the things that made responses to this question possible is that most people with MS who are heat sensitive can tell you the precise air temperature point at which their symptoms increase, although this does vary in some areas with highly variable humidity levels (hence the use of ranges rather than exact temperature points). 
Figure 7 Outside air temperature at which air conditioners are turned on

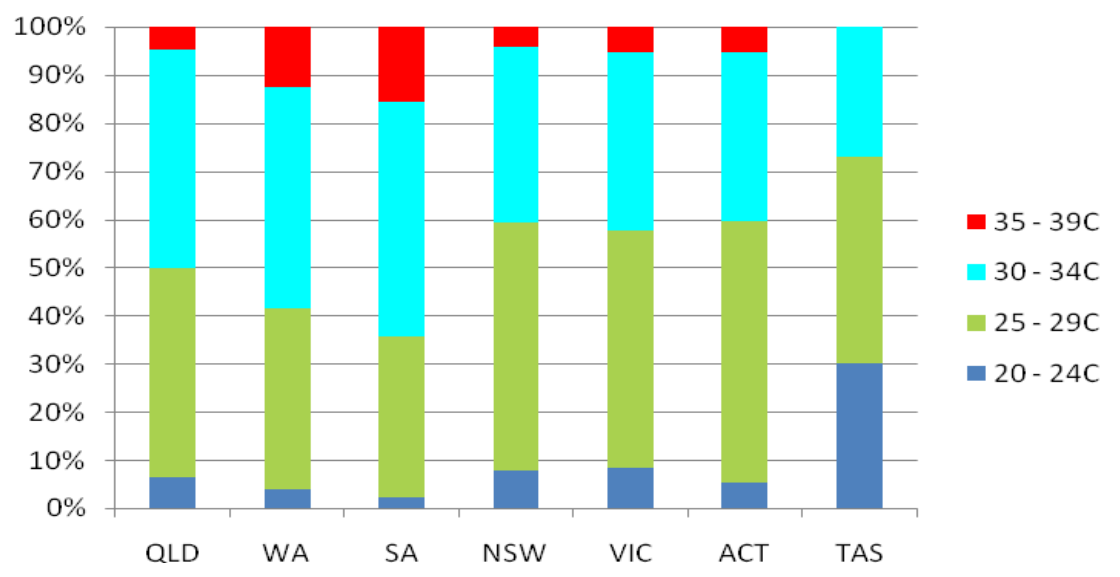

Nationally, the average temperature at which people with MS turned on their air conditioners was $29.2^{\circ} \mathrm{C}$, with many turning on their air conditioner at lower temperatures. The lowest average temperature when air conditions were turned on was Tasmania at $26.4^{\circ} \mathrm{C}$, while the highest was South Australia and WA at $30.6^{\circ} \mathrm{C}$ and $30.2^{\circ} \mathrm{C}$.

\subsubsection{Hours of air conditioner use}

Finally, the other major determinant of energy use and cost in relation to keeping cool is the number of hours that people with MS operate their air conditioners. In order to keep the survey form short and maximise response rates, usage data were collected in two-month increments (see Figure 7). Also, although data was collected for 12 months, only the 8 months of warmer weather and air conditioner use are reported here. As with all surveys requesting remembered or 'historical' information, it is possible that some recall bias may be present in the data, and this should be remembered when interpreting the results on air-conditioner usage. 
Figure 8 Imputed household average total hours of use for September to April

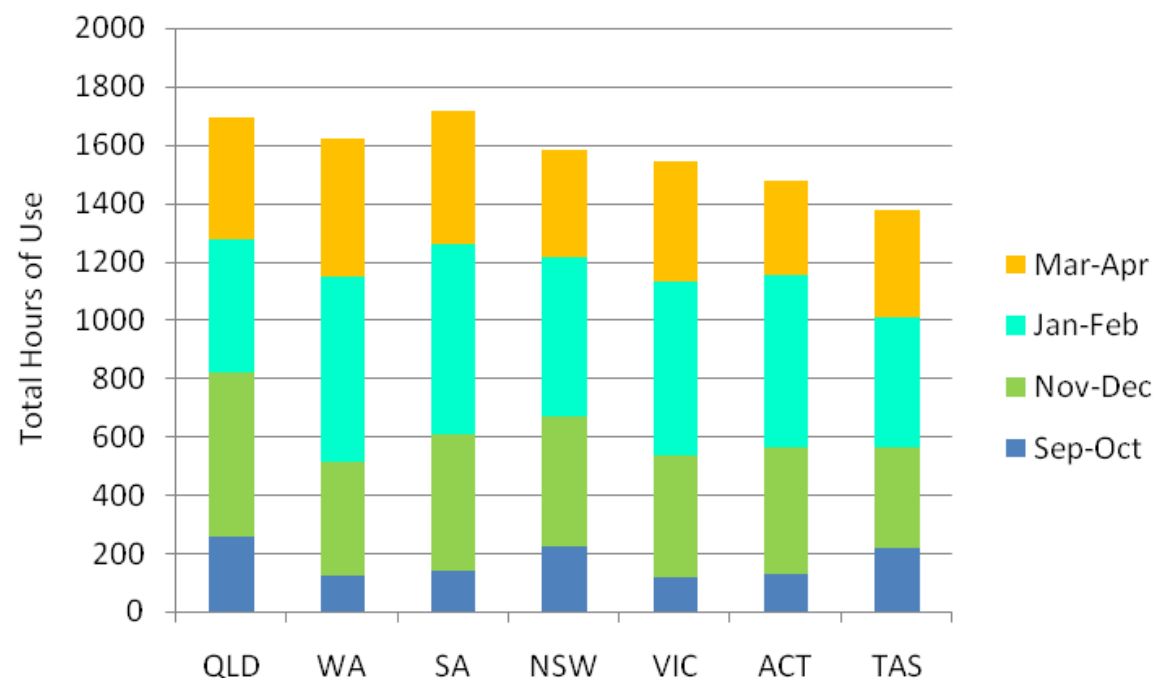

Note: This is an imputed average as it is derived using the midpoints from the categories selected by participants: 0 hours $=0$; $1-6$ hrs $=3.5$ hours; $7-12$ hours $=9.5 ; 13-18$ hours $=15.5 ; 19-24$ hours $=21.5$.

Figure 7 illustrates the changing hours of air conditioner use across the warm months and across regions. The average total hours of use nationally for people with MS was 1,616. The apparently high levels of use in November-December and March-April relative to JanuaryFebruary is an indication that it does not need to be extremely hot for people with MS to require the use of air conditioning. As noted in Figure 6, more than half of them (54\%) turn on their air conditioners before the external temperature reaches $30^{\circ} \mathrm{C}$.

In relation to Figure 7, other research for Victoria has found that the average number of hours air conditioners are used in the 'warmer months' is 107 hours (RMR 2008: p. ix). This data was based on recall and the completion of a questionnaire - similar to the KCS. While it is unclear exactly what is meant by 'warmer months' in RMR (2008), the imputed total for average Victorian household usage for someone with MS in the KCS was 1,544 hours from September to April (414 hours in November-December, 599 hours in January-February; and 413 in MarchApril). Given the similarity in methods and the similar possibility of recall bias, the difference in the results between the two surveys is striking: in Victoria people with MS average 1,544 hours 
compared to average household use of 107 hours. This suggests that people with MS may have their air conditioners on almost 15 times as much as the average household.

The high number of hours that air conditioners are used by MS households can be explained through several factors. First, people with MS are more likely to be home during working hours as $80 \%$ of them are unemployed within 10 years of diagnosis. Second, people with MS are more likely to stay home and indoors during hot weather to keep cool. Third, the threshold at which their symptoms increase is lower than the temperatures at which most people turn on their air conditioners. Finally, the use of air conditioners by people with MS (82\%) is also well above Australian air conditioner ownership (60\%).

\subsection{Minor home modifications for thermal efficiency}

Participants were also asked to identify minor home modifications (including existing construction elements) that related to their homes' thermal efficiency. For example, ceiling/roof insulation can reduce energy consumption up to $45 \%$ in summer and winter (ABS 2005). Table 4 describes the results from the KCS for people with MS; data in parentheses are general Australian household figures from ABS (2005).

Table 4 Percentage of people with minor home modifications

\begin{tabular}{lccccc}
\hline State & $\begin{array}{c}\text { External window } \\
\text { blinds, awnings, etc }\end{array}$ & $\begin{array}{c}\text { Internal window } \\
\text { blinds, drapes, etc }\end{array}$ & $\begin{array}{c}\text { Roof } \\
\text { insulation* }\end{array}$ & $\begin{array}{c}\text { Roof } \\
\text { vents }\end{array}$ & $\begin{array}{c}\text { Wall } \\
\text { insulation* }\end{array}$ \\
\hline Queensland & 31 & 78 & $58(41)$ & 27 & $15(11)$ \\
Western Australia & 30 & 84 & $75(65)$ & 17 & $11(6)$ \\
South Australia & 52 & 83 & $77(77)$ & 19 & $37(27)$ \\
New South Wales & 38 & 80 & $67(53)$ & 26 & $25(18)$ \\
Victoria & 48 & 79 & $72(71)$ & 12 & $32(29)$ \\
Australian Capital Territory & 40 & 86 & $86(78)$ & 7 & $53(34)$ \\
Tasmania & 17 & 86 & $77(73)$ & 6 & $38(25)$ \\
Australia & 40 & 80 & $70(59)$ & 19 & $27(19)$ \\
\hline
\end{tabular}

* Data in parentheses are from ABS (2005), Tables 2.11 and 2.14. ${ }^{\wedge}$ Australian figures exclude Northern Territory data. 
Comparing the national figures for roof and wall insulation to households that include a person with MS, the MS households seem to have taken extra steps to improve the thermal efficiency of their homes relative to the general population. Additionally it appears that the variations between regions for the KCS approximate national trends.

Also, although state-level details are not reported, ABS (2005) found that "outside awnings and/or shutters were the principal form of window protection applied in over $30 \%$ of dwellings in Australia, mainly in South Australia (SA) (43\% of dwellings) and Victoria (38\% of dwellings)" (p. 12). Again, at $52 \%$ for SA and $48 \%$ for Victoria, people with MS exceed the national trends in their efforts to keep cool.

\section{Estimated costs of air conditioning use by MS households}

\subsection{Base estimates}

Here we apply the survey results to model the costs of air conditioner use by people with MS (or MS households) ${ }^{10}$ and compare these costs to those for the average Australian household.

Hours of use. The basis of our cost calculations is the average hours of air conditioner use by MS households calculated from the KCS and reported in Section 3.4.5. Air conditioner use data collected by the KCS covered five ranges: 0 hours; 1-6 hours; 7-12 hours; 13-18 hours; 19 24 hours. Without knowing the distribution of use within these ranges, we chose midpoints for each range to indicate hours of use for each respondent: 0 hours; 3.5 hours; 9.5 hours; 15.5 hours; 21.5 hours. From this we are able to impute average total hours of use by MS household in each state; see Figure 7. Given that the choice of midpoints for each range is less than ideal, we test the sensitivity of this assumption below.

\footnotetext{
10 That is, a household that has at least one person with MS. We use this term interchangeably with the term "people with MS" when making comparisons to average households.
} 
Efficiency. Based on the Victorian Sustainable Energy Authority's 2002 Operating Costs of Electrical Appliances, costs per hour of air conditioner use were calculated based on two price points adjusted for efficiency. Published estimates of costs per hour were $\$ 0.33-\$ 0.35 /$ hour for 1-2 star rated air conditioners, and $\$ 0.24-\$ 0.27 /$ hour for $4-6$ star rated units. These cost estimates were extrapolated to an average cost for each of three sets of star ratings: $1-2$ stars $=$ $\$ 0.34 ; 3-4$ stars $=\$ 0.2975 ; 5-6$ stars $=\$ 0.255$ (i.e., the midpoint in each range). The age of air conditioners (see Section 3.4.3) was used as a proxy for efficiency, with 5-6 star weightings applied to those 3 years old or less, 3-4 stars for those 4-9 years old, and 1-2 stars for those 10 or more years old. A weighted average cost per hour of air conditioner operation for each state and territory was then calculated taking into account varying ages of air conditioners across states. ${ }^{11}$ The sensitivity of the results to variations in the efficiency weightings is tested below.

Because Victorian figures were used to estimate actual costs up to this point, these were then weighted for differential cooling loads, using Victoria as the reference point and AT as the weighting factor. ${ }^{12}$ The sensitivity of the adjustment for differential cooling loads using AT is tested below.

Electricity prices. Hours of air conditioner use were then multiplied by the different costs per hour for each state and territory (based on different weightings for efficiency). We assumed electricity supply prices of $\$ 0.15 / \mathrm{kWh}$ and $\$ 0.20 / \mathrm{kWh}$. This range approximates the lower and upper ends of domestic electricity pricing across Australia: tariffs vary within and between states

\footnotetext{
11 Note that these estimates from the Sustainable Energy Authority are based on reverse-cycle air conditioning for cooling a small-moderate sized space in an average sized house of 150 square metres (which is the average size of an Australian dwelling) with 2.4 metre high ceilings, and a cost of electricity at $\$ 0.15 / \mathrm{kWh}$. This was appropriate because when evaporative and ducted systems are excluded, $80 \%$ of respondents were cooling moderately sized spaces of one or two rooms and $20 \%$ were cooling 4 or more rooms.

12 Note that evaporative air conditioners were excluded from the calculation of weighted average cost per hour of air conditioner operation for each state and territory. This is because their operating costs are minimal relative to refrigerated/reverse-cycle air conditioners. Additionally, ducted cooling was excluded because, based on the findings of RMR (2008), there were five times as many evaporative as refrigerated/reverse-cycle ducted systems in Victoria. So it is likely that most of the ducted cooling systems are evaporative with the possible exception of NSW given its higher humidity levels in coastal areas.
} 
and territories, with a complex mix of flat rates, time of use rates, and off-peak rates. Results from the modelling are presented in Table 5.

Table 5 Estimated average cost of air conditioner use by MS households and all Australian households

\begin{tabular}{lccccc}
\hline \multirow{2}{*}{ Region } & \multicolumn{3}{c}{ MS households } & \multicolumn{2}{c}{ All Australian households\# } \\
\cline { 2 - 6 } & $\begin{array}{c}\text { Average } \\
\text { hours of use }\end{array}$ & $\begin{array}{c}\text { Cost at } \\
\$ 0.15 / \mathrm{kWh}\end{array}$ & $\begin{array}{c}\text { Cost at } \\
\$ 0.20 / \mathrm{kWh}\end{array}$ & $\begin{array}{c}\text { Cost at } \\
\$ 0.15 / \mathrm{kWh}\end{array}$ & $\begin{array}{c}\text { Cost at } \\
\$ 0.20 / \mathrm{kWh}\end{array}$ \\
\hline Queensland & 1,574 & $\$ 753$ & $\$ 1,004$ & $\$ 112$ & $\$ 149$ \\
Western Australia & 1,250 & $\$ 560$ & $\$ 747$ & $\$ 61$ & $\$ 82$ \\
South Australia & 1,430 & $\$ 570$ & $\$ 760$ & $\$ 80$ & $\$ 107$ \\
New South Wales & 1,362 & $\$ 489$ & $\$ 651$ & $\$ 17$ & $\$ 72$ \\
Victoria & 1,335 & $\$ 406$ & $\$ 541$ & $\$ 22$ & $\$ 29$ \\
Australian Capital Territory & 1,139 & $\$ 297$ & $\$ 396$ & $\$ 0$ & $\$ 0$ \\
Tasmania & 1,168 & $\$ 300$ & $\$ 401$ & $\$ 49$ & $\$ 66$ \\
Australia^ & 1,374 & $\$ 488$ & $\$ 650$ &
\end{tabular}

* Cost is not a direct multiplication of hours and cost $/ \mathrm{kWh}$ as air conditioners are not operating at full capacity at all times when they are on; see text for further details. ^ Australian average excludes Northern Territory. \# Sourced from DEWHA (2008), Table 9, p. 39: 'Space Cooling Energy Consumption in Petajules by State from 1990-2020' Data was converted to average household data by converting petajules to $\mathrm{kWh}$ and dividing by total households.

The results show the very significant impact that as little as a $\$ 0.05$ difference in price per $\mathrm{kWh}$ can make to overall cooling costs for MS households. This is of particular concern given rising electricity costs generally, and the impending introduction of smart meters and time-of-use peak pricing tariff structures in many jurisdictions. Table 5 also provides estimates of cooling costs for all Australian households in 2007 (DEWHA 2008) and is a useful comparison point in relation to people with MS.

In comparison to the average Australian household, the cost of keeping cool for people with MS is approximately 10 times higher. In Tasmania, the burden relative to average households is infinite given that cooling costs are zero for the average Tasmanian household. In Victoria, the cost of keeping cool for people with MS is approximately twenty-four times higher than average; in Queensland and SA, it is only seven times higher. This translates into a significant economic burden for people with MS with respect to keeping cool. Given these costs for MS households, it 
is all the more remarkable that there are no differences in air conditioner use between those who can most afford it (not likely to be concession eligible) and those who can least afford it (those likely be concession eligible). The most probable conclusion from this is that keeping cool is a very high priority for people with MS, irrespective of their capacity to pay. That is, people with MS try to keep cool out of medical need rather than for comfort.

\subsection{Sensitivity analysis}

There are a number of areas where the cost modelling described above may be sensitive to the assumptions made in calculating cooling costs for MS households, so it is appropriate to test how sensitive the cooling cost estimates are to these assumptions. We undertake sensitivity analysis in a systematic way by applying a Gaussian quadrature that chooses the optimal number of variations in parameter values required to estimate the means and standard deviations in cooling costs (DeVuyst and Preckel 1997). The procedure assumes that: (i) variations in cooling costs are well approximated by a third-order polynomial in the varying parameters; (ii) varying parameters have a symmetric distribution; (iii) parameters either have a zero correlation or are perfectly correlated within a specified range (e.g., $\pm 10 \%$ ) (Arndt and Pearson 1996).

Sensitivity analysis (Table 6) was undertaken for the three key parameters: (a) hours of use; (b) hourly costs with efficiency weightings; and (c) utilisation of average maximum AT to take into account climatic variables given that hourly costs with efficiency weightings were based on Victoria.

In testing the sensitivity of each parameter, we apply the mean $(\sigma)$ and standard deviation ( $\mu$ ) to calculate the $95 \%$ confidence interval assuming each cost estimate is approximately normally distributed. This seems a reasonable assumption given that the cost estimates move approximately linearly with variations in each parameter being tested. As a further indicator of the dispersion of the probability distribution, we also calculate the coefficient of variation $(\sigma / \mu)$. 
Table 6 Sensitivity analysis of average cost of air conditioner use by MS households at $\$ 0.15 / \mathbf{k W h}$ to various parameters

\begin{tabular}{|c|c|c|c|c|c|}
\hline Region & Mean $(\mu)$ & Standard deviation $(\sigma)$ & \multicolumn{2}{|c|}{$95 \%$ confidence interval $*$} & $\mathrm{CV}^{\wedge}$ \\
\hline & \multicolumn{5}{|c|}{ Hours of air conditioner use } \\
\hline Queensland & $\$ 753$ & $\$ 62$ & $\$ 630$ & $\$ 876$ & 0.08 \\
\hline Western Australia & $\$ 560$ & $\$ 46$ & $\$ 469$ & $\$ 652$ & 0.08 \\
\hline South Australia & $\$ 570$ & $\$ 47$ & $\$ 477$ & $\$ 663$ & 0.08 \\
\hline New South Wales & $\$ 489$ & $\$ 40$ & $\$ 409$ & $\$ 568$ & 0.08 \\
\hline Victoria & $\$ 406$ & $\$ 33$ & $\$ 340$ & $\$ 472$ & 0.08 \\
\hline Tasmania & $\$ 301$ & $\$ 25$ & $\$ 252$ & $\$ 350$ & 0.08 \\
\hline Australian Capital Territory & $\$ 297$ & $\$ 24$ & $\$ 249$ & $\$ 346$ & 0.08 \\
\hline \multirow[t]{2}{*}{ Australia } & $\$ 488$ & $\$ 40$ & $\$ 408$ & $\$ 567$ & 0.08 \\
\hline & \multicolumn{5}{|c|}{ Average cost per hour weighted for efficiency } \\
\hline Queensland & $\$ 753$ & $\$ 62$ & $\$ 630$ & $\$ 876$ & 0.08 \\
\hline Western Australia & $\$ 560$ & $\$ 46$ & $\$ 469$ & $\$ 652$ & 0.08 \\
\hline South Australia & $\$ 570$ & $\$ 47$ & $\$ 477$ & $\$ 663$ & 0.08 \\
\hline New South Wales & $\$ 489$ & $\$ 40$ & $\$ 409$ & $\$ 568$ & 0.08 \\
\hline Victoria & $\$ 406$ & $\$ 33$ & $\$ 340$ & $\$ 472$ & 0.08 \\
\hline Australian Capital Territory & $\$ 297$ & $\$ 24$ & $\$ 249$ & $\$ 346$ & 0.08 \\
\hline Tasmania & $\$ 301$ & $\$ 25$ & $\$ 252$ & $\$ 350$ & 0.08 \\
\hline \multirow[t]{2}{*}{ Australia } & $\$ 488$ & $\$ 40$ & $\$ 408$ & $\$ 567$ & 0.08 \\
\hline & \multicolumn{5}{|c|}{ Average cost per hour weighted for apparent temperature } \\
\hline Queensland & $\$ 620$ & $\$ 109$ & $\$ 402$ & $\$ 838$ & 0.18 \\
\hline Western Australia & $\$ 475$ & $\$ 69$ & $\$ 336$ & $\$ 614$ & 0.15 \\
\hline South Australia & $\$ 507$ & $\$ 51$ & $\$ 405$ & $\$ 610$ & 0.10 \\
\hline New South Wales & $\$ 451$ & $\$ 31$ & $\$ 388$ & $\$ 513$ & 0.07 \\
\hline Victoria & $\$ 406$ & $\$ 0$ & $\$ 406$ & $\$ 406$ & 0.00 \\
\hline Australian Capital Territory & $\$ 325$ & $\$ 23$ & $\$ 280$ & $\$ 371$ & 0.07 \\
\hline Tasmania & $\$ 336$ & $\$ 29$ & $\$ 279$ & $\$ 394$ & 0.09 \\
\hline Australia & $\$ 454$ & $\$ 27$ & $\$ 400$ & $\$ 509$ & 0.06 \\
\hline
\end{tabular}

* The confidence interval assumes that the cost estimate is approximately normally distributed, i.e., approximately symmetrically distributed. Thus, the upper and lower ranges $=\mu \pm 2 \sigma .{ }^{\wedge}$ Coefficient of variation: $\sigma / \mu$.

The sensitivity analysis indicates that, in general, the modelling is highly robust with the results being relatively insensitive to variations in each parameter. For example, in relation to hours of use in NSW the mean cost is $\$ 489$ with a standard deviation of $\$ 40$. This gives a $95 \%$ confidence interval of $\$ 409-568$, which means that we can be $95 \%$ confident that the actual costs are in this range. The results for other states and nationally are similarly robust for variations in hour of use. This is also true for variations in efficiency weightings. The results for variations in 
apparent temperature are also highly robust except for Queensland and WA, where they show somewhat larger values for the coefficient of variation, and therefore somewhat larger confidence intervals. This result is consistent with much higher apparent temperature in Queensland and WA compared to the other states.

\section{Conclusion}

Heat intolerance is a major medical problem affecting people with MS. As little as $0.2^{\circ} \mathrm{C}-$ $0.5^{\circ} \mathrm{C}$ increase in core body temperature significantly increases MS symptoms and significantly reduces the capacity of people with MS to participate in social, household and work activities, as well as increasing their need for pharmaceuticals and medical services. Consequently, the use of air conditioners, with all associated purchase and operating costs, is usually a necessity for people with MS. The costs of MS households running their air conditioners are an additional diseaserelated expense that must be met on top of other out-of-pocket disease-related expenses. All of these expenses must be met from lower than average incomes that people with MS earn. These out-of-pocket costs, combined with (a) relatively rapidly rising electricity costs, and (b) the increasing number of hot days and nights due to climate change, suggest that, over time, people with MS on low incomes are facing greater economic disadvantage in trying to keep cool on hot days and nights. This work is an attempt to quantify the current degree of economic disadvantage in trying to keep cool for Australians with MS.

Despite the importance of keeping cool for people with MS, no previous research (that we are aware of) has explored and described the use of air conditioners by people with MS across Australia, or in other countries, let alone attempted to quantify the degree of economic disadvantage faced by people with MS in trying to keep cool. Thus, this work is unprecedented. To address this absence, the Keeping Cool Survey was conducted in 2008. The survey found that $90 \%$ of the 20,000 people with MS in Australia are sensitive to heat, and run their air 
conditioners more frequently and for longer periods than most Australians. Nationally, people with MS averaged 1,616 hours of air conditioner use annually; no data exists on average Australian household usage of air conditioners. In Victoria, the annual average for MS households was 1,544 hours of air conditioner use; this compares with an average use over the warmer months of 107 hours for all Victorian households. This suggests that people with MS might run their air conditioners 15 times as much as the average Australian household. To help minimise these costs, people with MS make minor home modifications to improve the thermal efficiency of their homes more often than the average Australian household. The Keeping Cool Survey also found no difference in patterns of air conditioner ownership and use between people with MS on lower incomes and those on higher incomes. This reinforces how important keeping cool is in their daily lives.

Applying the results of the Keeping Cool Survey, we model the costs of keeping cool for people with MS. Our estimates suggest that average costs for people with MS across Australia from September to April for running their air conditioners are between $\$ 488$ and $\$ 650$. Not surprisingly, costs are higher in the hotter areas (\$753-\$1,004 in Queensland) and lower in cooler areas (\$297-\$396 in the Australian Capital Territory). For 2007, the estimated average cost of cooling for all Australian households was \$49-\$66. This indicates that, on average, people with MS are estimated to spend around 10 times more on keeping cool than the average Australian household.

We apply sensitivity analysis on these estimates by systematically testing the variation in cooling costs due to variation in key parameters. The sensitivity analysis indicates that the modelling is highly robust with the results being relatively insensitive to variations in each parameter. For example, in relation to hours of use nationally, the mean cost is $\$ 488$ with a standard deviation of $\$ 40$ assuming an electricity price of $\$ 0.15 / \mathrm{kWh}$. This gives a $95 \%$ 
confidence interval of \$408-\$567. Thus, people with MS may spend between eight to twelve times more on keeping cool than the average Australian household.

Given that more than half of Australians with MS have low incomes, the economic disadvantage suffered by people with MS in trying to keep cool raises a number of public policy issues and challenges. This includes: ensuring that community service obligations to people who are heat intolerant are met in a way that is effective and equitable; maximising the efficiency of cooling for these households to minimise both the economic and environmental costs; and minimising the impact of catastrophic events such as power blackouts on this group.

These public policy issues and challenges must be resolved in ways that will continue to be effective and equitable in a rapidly changing policy environment that includes: the development of national electricity markets; the implementation of smart meters, and time-of-use peak pricing tariff structures; rapidly increasing electricity costs now and into the foreseeable future; and possibly more hot days and nights nationally, increasing the need for medical cooling and the associated increasing costs for households. The estimates presented here are an important input into any policy responses that aim to reduce the burden of heat intolerance in an effective and equitable manner.

Public policy responses to heat intolerance for low income households will be most effective and equitable if they are aimed broadly at the wide range of people who are heat intolerant, such as those serviced through the existing concession programs in Victoria and Western Australia. Current public policy responses, such as electricity rebates, are a useful and effective means of assisting people with heat intolerance, as reflected by experiences with existing programs. Such rebates must be set at meaningful levels and be regularly adjusted to take into account residential electricity price increases. Further, such rebates would need to be developed and implemented in all states and territories. 


\section{References}

Access Economics 2005, Acting Positively: Strategic Implications of the Economic Costs of Multiple Sclerosis in Australia, Access Economics, Canberra.

Arndt, C. and Pearson, K. (1996), How to Carry Out Systematic Sensitivity Analysis via Gaussian Quadrature and GEMPACK, GTAP Technical Paper No. 3, Purdue University, West Lafayette.

ABS (Australian Bureau of Statistics) 2005, Environmental Issues: People's Views and Practices, publication number 4602.0, ABS, Canberra.

ABS 2009, Australian Economic Indicators, Cat. no. 1350.0, ABS, Canberra.

Baker, D.G. 2002, 'Multiple sclerosis and thermoregulatory dysfunction', Journal of Applied Physiology, vol. 92, pp. 1779-1780.

de Dear, R. and Hart, M. 2002, Appliance Electricity End-Use: Weather and Climate Sensitivity, report prepared by Macquarie Research Ltd (through the Division of Environmental and Life Sciences at Macquarie University) for the Australian Greenhouse Office, Canberra.

De Judicibus, M.A. and McCabe, M.P. 2007, 'The impact of financial costs of multiple sclerosis on quality of life', International Journal of Behavioural Medicine, vol. 14, pp. 3-11.

DeVuyst, E.A. and Preckel, P.V. (1997). Sensitivity analysis revisited: a quadrature-based approach, Journal of Policy Modelling 19, 175-85.

Dufty, G. 2009, EWOV - Hardship: Where Are We on the Journey? Cost Trends for Essential Items Implications for Victorian Households, St Vincent de Paul Society, Melbourne.

DEWHA (Department of the Environment, Water, Heritage and the Arts) 2008, Energy Use in the Australian Residential Sector 1986-2020, Commonwealth of Australia.

Edlich, R.F., Buschbacher, R.M., Cox, M.K., Long, W.B., Winters, K.L. and Becker, D.G., 'Strategies to reduce hyperthermia in ambulatory multiple sclerosis patients', Journal of Long-Term Effects of Medical Implants, vol. 14, no. 6, pp. 467-479.

Guthrie, C.T. and Nelson, D.A. 1995, 'Influence of temperature changes on multiple sclerosis: critical review of mechanisms and research potential', Journal of the Neurological Sciences, vol. 129, pp. $1-8$.

Henke, A.F., Cohle, S.D. and Cottingham, S.L. 2000, 'Fatal hyperthermia fatal to sunbathing in a patient with multiple sclerosis', American Journal of Forensic Medicine and Pathology, vol. 21, no. 3, pp. 204-206.

IPART (Independent Pricing and Regulatory Tribunal) 2009, Market-based Electricity Purchase Cost Allowance - 2009 Review: Regulatory Electricity Retail Tariffs and Charges for Small Customers 2007 to 2010: Electricity - Draft Report, IPART NSW, Sydney.

Johnson, K.L. and Fraser, R.T. 2005, 'Mitigating the impact of multiple sclerosis on employment', Physical Medicine and Rehabilitation Clinics of North America, vol. 16, pp. 571-582. 
Kohlemeier, R.E., DiMaio, V.J.M and Kagan-Hallet, K. 2000, 'Fatal hyperthermia in hot baths in individuals with multiple sclerosis', American Journal of Forensic Medicine and Pathology, vol. 21, no. 3, pp. 201-203.

Lerdal, A., Gulowsen Celius, E., Krupp, L. and Dahl, A.A. 2007, 'A prospective study of patterns of fatigue in multiple sclerosis', European Journal of Neurology, vol. 14, pp. 1338-1343.

Meyer-Heim, A, Rothmaier, M., Weder, M. Kool, J., Schenk, P., and Kesselring, J. 2007, 'Advanced lightweight cooling-garment technology: functional improvements in thermosensitive patients with multiple sclerosis', Multiple Sclerosis, vol. 13, no. 2, pp. 232-237.

Ministerial Council on Energy 2008, Energy Community Service Obligations: National Framework, response to the Council of Australian Governments' request for a national review of community service obligations and advice on best practice, sourced at http://www.ret.gov.au/Documents/mce/_documents/MCE\%5FEnergy\%5FCommunity\%5FServices \%5FObligation20080929151353.pdf

NASA/MS Cooling Study Group [Schwid, S.R., Petrie, M.D., Murray, R., Leitch, J., Bowen, J., Alquist, A., Pelligrino, R., Roberts, A., Harper-Bennie, J., Milan, M.D., Guisado, R., Luna, B., Mongomery, L., Lamparter, R., Ku, Y.Tl, Lee, H., Godlwater, D., Cutter, G., Webbon, B.] 2003, ‘A randomized controlled study of the acute and chronic effects of cooling therapy for MS', Neurology, vol. 60, no. 12, pp. 1955-1960.

Ogawa, G., Mochizuki, H., Kanzaki, M., Kaida, K., Motoyoshi, K. and Kamakura, K. 2003, 'Seasonal variation of multiple sclerosis exacerbations in Japan', Neurological Science, vol. 24, pp. 417-419.

Petrilli, S., Durufle, A., Nicolas, B., Robineau, S., Kerdoncuff, V., LeTallec, H., Lassalle, A. and Gallien, P. 2004, 'Influence of temperature changes on clinical symptoms in multiple sclerosis, an epidemiologic study', Annales de readaption et de medicine physique, vol. 47, pp. 204-208.

RMR (Roy Morgan Research) 2008, Victorian Utility Consumption Household Survey 2007, RMR, Melbourne.

Simmons, R.D., Ponsonby, A.L., van der Mei, I.A.F. and Sheridan, P. 2001, 'What affects your MS? Response to an anonymous, Internet-based epidemiological survey', Multiple Sclerosis, vol. 10, pp. $202-211$.

Summers, M. and Simmons, R. 2009, Keeping Cool Survey: Air Conditioner Use by Australians with MS, MS Australia, Melbourne.

Tataru, N., Vidal, C., Decavel, P., Berger, E. and Rumbach, L. 2006, 'Limited impact of the summer heat wave in France (2003) on hospital admissions and relapses for multiple sclerosis', Neuroepidemiology, vol. 27, no. 1, pp. 28-32.

Visscher, B.R., Detels, R., Clark, V.A., Malmgren, R., Dudley, J.P. and Valdiviezo, N.L. 1983, 'Role of heat in multiple sclerosis symptoms in a high- and a low-prevalence area', Neuroepidemiology, vol. 2, pp. 56-61. 
Ya-Ping, J., de Pedro-Cuesta, J., Soderstrom, M., Stawiarz, L. and Link, H. 2000, 'Seasonal patterns in optic neuritis and multiple sclerosis: a meta-analysis', Journal of the Neurological Sciences, vol. 181, pp. 56-64. 